\title{
Short communication: Validation of a test-day milk test for $\beta$-hydroxybutyrate for identifying cows with hyperketonemia
}

\author{
D. L. Renaud, D. F. Kelton, and T. F. Duffield* \\ Department of Population Medicine, University of Guelph, Guelph, Ontario, N1G 2W1, Canada
}

\section{ABSTRACT}

Subclinical ketosis is a common metabolic disorder affecting dairy cattle that results in a greater risk for the development of subsequent metabolic and infectious disease. Canwest Dairy Herd Improvement (DHI; Guelph, ON, Canada) has begun to use an infrared test (MilkoScan FT600, Foss Analytical A/S, Hillerød, Denmark) applied to metered composite milk samples to detect $\beta$-hydroxybutyrate (BHB) levels as a herd surveillance test for hyperketonemia. However, the test has not been compared with the gold standard, serum $\mathrm{BHB}$ as determined in a reference diagnostic laboratory. The objective of this cross-sectional diagnostic accuracy study was to validate the DHI milk BHB test to identify cows with hyperketonemia as determined by quantification of BHB in serum. A total of 316 cows from 17 dairy herds in southwestern Ontario had a milk and blood sample taken. Milk was collected at a routine DHI test, and blood from the same cow was sampled within $24 \mathrm{~h}$ of the milk test. The BHB concentration in milk was determined using the DHI milk BHB test, and serum was sent to the Animal Health Laboratory at the University of Guelph (Guelph, ON, Canada). A nonparametric receiver operating characteristic curve was generated to compare DHI milk BHB concentrations with serum BHB concentrations. Overall, a total of 34 cows (11\%) had a level of serum BHB $\geq 1.2 \mathrm{mmol} / \mathrm{L}$. The concentration of DHI milk BHB was moderately correlated with the concentration of serum BHB, yielding a coefficient of determination value of 0.61 . The optimal cut point for determining hyperketonemia $(\geq 1.2 \mathrm{mmol} / \mathrm{L})$ on the DHI milk BHB test was $\geq 0.14$ $\mathrm{mmol} / \mathrm{L}$, yielding a sensitivity of $81 \%$ and specificity of $92 \%$. The performance of the DHI milk BHB test varied depending on the days in milk (DIM) of the cows tested, with a higher specificity being found in cows that were $\leq 25$ DIM compared with cows tested $>25$ DIM. If the herd-level prevalence of hyperketonemia

Received March 20, 2018.

Accepted October 3, 2018.

*Corresponding author: tduffiel@uoguelph.ca was $\geq 14 \%$, the DHI milk BHB test had an improved sensitivity when compared with a herd-level prevalence of $<14 \%$. This study demonstrates that the DHI milk BHB test is a reliable measure for evaluating hyperketonemia using routine DHI milk samples and could be used as a herd-level monitoring tool for ketosis when evaluating nutritional management or preventative medicine strategies.

Key words: ketosis, milk, dairy cow

\section{Short Communication}

Subclinical ketosis is a common metabolic disease affecting more than $40 \%$ of dairy cattle in early lactation (McArt et al., 2012a; Gordon et al., 2013). Cows with elevated levels of blood ketone bodies are at greater risk for the development of abomasal displacement, metritis, reduced milk yield, and reduced pregnancy risk (Duffield et al., 2009; Ospina et al., 2010; McArt et al., 2012a). These negative sequelae lead to a cost of $\$ 289$ per case of ketosis (McArt et al., 2015).

Subclinical ketosis is diagnosed through the measurement of circulating levels of BHB. Gold standard tests rely on the quantification of BHB in serum or plasma under laboratory settings (Duffield et al., 2009). However, several cow-side ketosis tests are available for milk, blood, and urine (Tatone et al., 2016). One of the challenges of these tests is that they are labor intensive, especially for herd-level monitoring.

Many DHI organizations offer clients an infrared test to detect milk BHB as a herd surveillance test. The test uses regularly collected milk samples from routine herd DHI tests. Using a cut point of $\geq 0.15 \mathrm{mmol} / \mathrm{L} \mathrm{BHB}$ at first DHI test, Tatone et al. (2017) reported a cow-level ketosis prevalence of $21 \%$ using milk samples collected from all Ontario farms enrolled in DHI. However, this threshold was based on the optimal Fourier-transform infrared spectroscopy threshold to predict milk BHB $>0.10 \mathrm{mmol} / \mathrm{L}$, and the DHI milk BHB test has not been evaluated in comparison with a gold standard serum laboratory test.

The objective of this cross-sectional diagnostic accuracy study was to validate the DHI milk BHB test 
to identify cows with hyperketonemia (defined as blood BHB $\geq 1.2 \mathrm{mmol} / \mathrm{L}$; LeBlanc et al., 2005) as determined by quantification of BHB in serum.

This study was conducted in cooperation with a veterinary clinic in southwestern Ontario from February to November 2016. A total of 320 cows from 17 dairy herds were sampled. Milk samples were collected at the regular DHI test, preserved with bronopol tablets (Brotab, Systems Plus, Baden, ON, Canada), and transported to the CanWest DHI laboratory (Guelph, ON, Canada). The concentration of BHB in milk samples was measured $(\mathrm{mmol} / \mathrm{L})$ using the DHI milk BHB test (MilkoScan FT600, Foss Analytical A/S, Hillerød, Denmark). Other data that were collected for each cow included milk production, DIM, milk fat, milk protein, and SCC. Within $24 \mathrm{~h}$ of the DHI test, animal health technicians collected blood samples via coccygeal venipuncture into sterile plastic vacuum tubes without anticoagulant (BD Vacutainer; Becton Dickinson, Franklin Lakes, NJ). The sample was transported on ice, separated, frozen, and stored at $-20^{\circ} \mathrm{C}$ until analysis at the Animal Health Laboratory (Guelph, ON, Canada). The serum BHB was measured using an automated biochemistry analyzer (Cobas 6000 c501 biochemistry analyzer, Roche Diagnostics, Laval, QC, Canada). Using the method described by Buderer (1996), the required sample size was determined to be 308 cows, assuming a ketosis $(\geq 1.2 \mathrm{mmol} / \mathrm{L})$ prevalence of $20 \%$ (Tatone et al., 2017), the predicted sensitivity and specificity of the DHI milk BHB test to identify ketotic cows to both be $80 \%$, and the clinically acceptable width of the $95 \%$ confidence intervals for sensitivity and specificity to be no larger than $10 \%$.

All statistical analyses were completed using Stata 14 (StataCorp LP, College Station, TX). Data were imported from Microsoft Excel (Microsoft Corp., Redmond, WA) into Stata 14 and checked for completeness. To evaluate the correlation between milk and serum BHB concentrations, a simple linear regression was modeled with serum BHB concentration as the predictor and milk BHB concentration as the outcome of interest. The assumptions of normality and homoscedasticity of the residuals were tested using a Shapiro-Wilk test and Cook-Weisberg test. A nonparametric receiver operating characteristic (ROC) curve was generated to compare the concentrations of milk BHB as determined by the DHI milk test and serum BHB concentrations from the laboratory method and to determine the sensitivity and specificity of the DHI milk BHB test in classifying cows as having hyperketonemia ( $\geq 1.2 \mathrm{mmol} / \mathrm{L}$ ) or not (Dohoo et al., 2009). The cut point for the DHI milk BHB test was selected using Youden's index (Youden, 1950) to optimize both sensitivity and specificity (Florkowski, 2008). The calculation of the test characteristics was conducted using the entire data set and was stratified at the mean value for herd-level prevalence of hyperketonemia and DIM at routine DHI test.

A total of 17 dairy herds enrolled 316 cows, with all cows that were $<50$ DIM being sampled. A range of 7 to 70 cows were enrolled per farm. Enrolled cows were producing on average $36 \mathrm{~kg}$ (SD: $10 \mathrm{~kg}$ ), $1.5 \mathrm{~kg}$ (SD: $0.5 \mathrm{~kg}$ ), and $1.2 \mathrm{~kg}$ (SD: $0.3 \mathrm{~kg}$ ) of milk, milk fat, and milk protein, respectively. They also had a mean DIM of 25 (SD: 12 DIM) and SCC of 202,441 cells/mL (SD: 518,193 cells $/ \mathrm{mL}$ ). Of the animals, $33 \%$ were firstlactation heifers $(\mathrm{n}=101), 30 \%$ were second-lactation cows $(\mathrm{n}=94)$, and $37 \%$ were third-lactation or greater cows $(\mathrm{n}=114)$.

Using a threshold of $\geq 1.2 \mathrm{mmol} / \mathrm{L}$ serum BHB, $11 \%$ of cows $(\mathrm{n}=34$ cows $)$ tested positive for hyperketonemia (Table 1). Herd-level prevalence of hyperketonemia ranged from 0 to $43 \%$. The mean serum BHB concentration was $0.77 \mathrm{mmol} / \mathrm{L}$ (SD: $0.80 \mathrm{mmol} / \mathrm{L})$. The mean milk BHB concentration was $0.10 \mathrm{mmol} / \mathrm{L}$ (SD: $0.06 \mathrm{mmol} / \mathrm{L})$. Using the threshold of milk BHB $\geq 0.15$ $\mathrm{mmol} / \mathrm{L}$ (Tatone et al., 2017), the apparent prevalence of ketosis was $13.1 \%$ of cows $(\mathrm{n}=40$ cows $)$ when using the DHI milk BHB test. Table 1 describes the number of cows testing positive for hyperketonemia and ketosis using the DHI milk BHB test in the different groups described below.

The concentration of BHB in DHI milk samples was moderately correlated with serum BHB concentrations, yielding a coefficient of determination value of 0.63 , indicating that the model with serum BHB explained $63 \%$ of the variation in the level of milk BHB. The area under the curve (AUC) for the ROC curve was 0.94 (95\% CI: 0.89-0.98). Using Youden's index, a cut point of $0.14 \mathrm{mmol} / \mathrm{L}$ for the DHI milk BHB test maximized the sensitivity and specificity of the test. The test characteristics are summarized in Table 2 .

A wide range of DIM was tested, with the minimum being 5 DIM and maximum being 47 DIM. The DIM was split at the mean of 25 DIM to create low- $(<25$ DIM) and high- ( $\geq 25$ DIM) DIM data sets. As DIM data were missing for 7 cows, they were excluded from this analysis. The ROC curve, using the data from the low-DIM cows, generated an AUC of 0.94 (95\% CI: 0.89-0.99), and using Youden's index, a cut point of $0.14 \mathrm{mmol} / \mathrm{L}$ for the DHI milk BHB was selected. The prevalence of hyperketonemia was $14 \%(\mathrm{n}=23)$ in the low-DIM category (Table 1). The cows in the high-DIM data set had a prevalence of hyperketonemia of $6 \%$ (n = 9; Table 1). The AUC was 0.91 (95\% CI: 0.83-0.98), and using Youden's index, a cut point of $0.10 \mathrm{mmol} / \mathrm{L}$ 
Table 1. Number of cows testing positive for hyperketonemia and testing positive for ketosis using DHI milk BHB test from 17 dairy herds located in southwestern Ontario, Canada

\begin{tabular}{lccc}
\hline Category & No. & $\begin{array}{c}\text { No. of cows with } \\
\text { hyperketonemia }\end{array}$ & $\begin{array}{c}\text { No. of cows testing positive } \\
\text { using DHI milk BHB test }^{2}\end{array}$ \\
\hline Overall $^{3}$ & 316 & 34 & 48 \\
$\quad$ Low & & & 33 \\
High & 156 & 23 & 49 \\
Herd prevalence & 150 & 9 & 13 \\
$\quad$ Low & 231 & 8 & 24 \\
$\quad$ High & 85 & 26 & \\
\hline
\end{tabular}

${ }^{1}$ Defined as blood BHB $\geq 1.2 \mathrm{mmol} / \mathrm{L}$.

${ }^{2}$ Defined as $\geq 0.14 \mathrm{mmol} / \mathrm{L}$ milk BHB for overall, low-DIM, and high-prevalence categories; $\geq 0.10 \mathrm{mmol} / \mathrm{L}$ for high-DIM category; and $\geq 0.17 \mathrm{mmol} / \mathrm{L}$ for low herd prevalence category.

${ }^{3}$ Low $=$ cows were $<25$ DIM at the regular DHI test; high $=$ cows were $\geq 25$ DIM at the regular DHI test.

${ }^{4}$ Low $=$ cows were in herds where $<14 \%$ of cows tested positive for hyperketonemia at the regular DHI test; high $=$ cows were in herds where $\geq 14 \%$ of cows tested positive for hyperketonemia at the regular DHI test.

was generated. These test characteristics are also included in Table 2.

The mean herd-level prevalence of hyperketonemia was $14 \%$, and this was used to split the herds into high- and low-prevalence herds. In the low-prevalence herds $(<14 \%), 3.0 \%$ of cows $(\mathrm{n}=8)$ tested positive for hyperketonemia (Table 1). The AUC was $0.94(95 \%$ CI: $0.86-0.99$ ), and a cut point of $0.17 \mathrm{mmol} / \mathrm{L}$ was selected based on Youden's index. The high-prevalence herds $(\geq 14 \%)$ had a prevalence of $30.5 \%$ ( $\mathrm{n}=26$ cows; Table 1). The AUC was 0.93 (95\% CI: 0.87-0.99), and using Youden's index a cut point of $0.14 \mathrm{mmol} / \mathrm{L}$ was selected. These test characteristics can also be found in Table 2.
This study demonstrates that the DHI milk BHB test is moderately correlated with laboratory-derived serum $\mathrm{BHB}$ and that the test performs well when compared with the gold standard. The positive predictive value, especially when evaluating the overall data set, was low. This is a reflection of the low prevalence of hyperketonemia in this study population (Dohoo et al., 2009).

A limitation of this study is the potential for a change in the concentrations of BHB during the 24-h time period that elapsed between milk collection and blood sampling. Studies have demonstrated variations in BHB concentrations throughout the day with respect to feeding time (Christensen et al., 1997; Eicher et al., 1999). However, no differences in the propor-

Table 2. Test characteristics (95\% CI in parentheses) for the DHI milk BHB test (MilkoScan FT600, Foss Analytical A/S, Hillerød, Denmark) using milk collected from 316 Holstein cows at routine DHIA tests

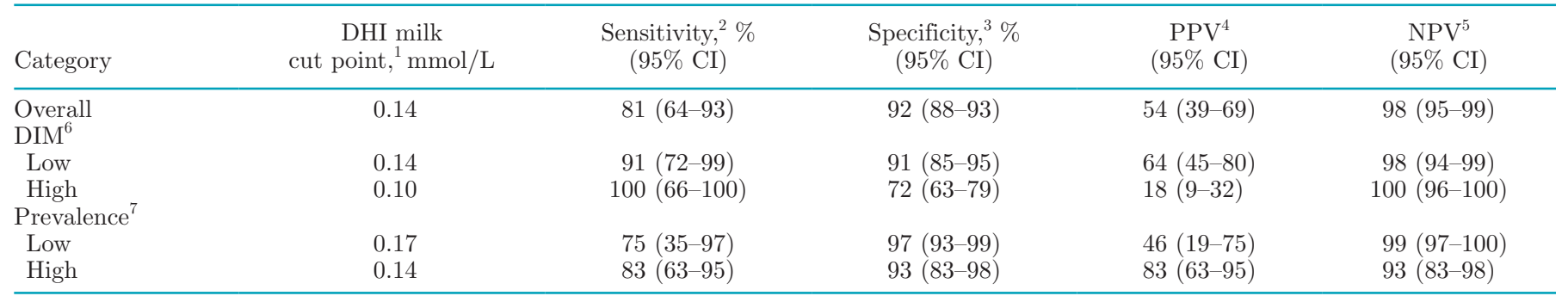

${ }^{1}$ Defined as the threshold selected using Youden's index, which used the concentrations of milk BHB as determined by the DHI milk test to classify cows as having hyperketonemia $(\geq 1.2 \mathrm{mmol} / \mathrm{L})$ or not.

${ }^{2}$ Defined as the probability of testing positive for hyperketonemia using the DHI milk BHB test given that the cow has a serum level of $\geq 1.2$ $\mathrm{mmol} / \mathrm{L}$.

${ }^{3}$ Defined as the probability of testing negative for hyperketonemia using the DHI milk BHB test given that the cow has a serum level of $<1.2$ $\mathrm{mmol} / \mathrm{L}$.

${ }^{4}$ Positive predictive value; defined as the probability that the cow has a serum level of BHB $\geq 1.2 \mathrm{mmol} / \mathrm{L}$ given that the cow tested positive for ketosis according to the DHI milk BHB test.

${ }^{5}$ Negative predictive value; defined as the probability that the cow has a serum level of $\mathrm{BHB}<1.2 \mathrm{mmol} / \mathrm{L}$ given that the cow tested negative for ketosis according to the DHI milk BHB test.

${ }^{6}$ Low $=$ cows were $<25$ DIM at the regular DHI test; high $=$ cows were $\geq 25$ DIM at the regular DHI test.

${ }^{7}$ Low $=$ cows were in herds where $<14 \%$ of cows tested positive for hyperketonemia at the regular DHI test; high $=$ cows were in herds where $\geq 14 \%$ of cows tested positive for hyperketonemia at the regular DHI test. 
tions of hyperketonemia were observed when cows were sampled $1 \mathrm{~h}$ before feeding and 4 and $10 \mathrm{~h}$ following feeding (Quiroz-Rocha et al., 2010). Another limitation to consider is the low prevalence of hyperketonemia in the study population, which could have contributed to a reduction in statistical power needed to validate the DHI milk BHB test. A prevalence of $20 \%$ was used to guide the number of cows enrolled in this study; however, in the study population the prevalence of hyperketonemia was $11 \%$. Using the sample size formula by Buderer (1996) along with the sensitivity, specificity, and prevalence found in this study, we would need to enroll a much larger number of cows to achieve adequate power. Nonetheless, given the logistical challenges associated with collecting DHI milk samples and blood samples in synchrony on many dairy herds and the lack of information surrounding the utility of the DHI milk BHB test, we believe this provides some evidence that this test would be useful as a herd-level monitoring tool, especially when testing herds that have a high prevalence of hyperketonemia and in cows that are in early lactation.

Routine data collection on dairy herds is necessary to provide early detection of health problems and the opportunity to intervene to limit the consequences of health challenges before they can reduce performance (LeBlanc, 2010). Use of cow-side tests has been shown to be an effective method for monitoring and treating ketosis; however, despite there being evidence that performing these tests on a routine basis is cost effective (McArt et al., 2014), a lack of labor on many dairy farms limits the ability of the producer to generate data to understand the ketosis challenges on their farm. Hence, having a validated DHI milk test, which can be done on routinely collected samples (no additional farm labor is required), may allow for more data to be generated that producers and advisors could use to make proactive and informed management decisions. Although DHI milk testing for BHB cannot replace onfarm ketone testing, largely because of the prolonged interval between DHI tests and the 48-h delay from sample collection and receiving the ketone levels from DHI, it can be useful for classifying herds into risk categories and for ongoing monitoring of low-risk herds.

The performance of the DHI milk test improved when it was used in higher prevalence herds and in cows in early lactation. As the peak incidence of subclinical ketosis is on 5 DIM (McArt et al., 2012b), it is likely that tests evaluating ketosis should be constrained to the initial portion of lactation. If the DHI milk BHB test is used beyond 26 DIM, a higher number of false positives should be expected and a cut point of $0.10 \mathrm{mmol} / \mathrm{L}$ BHB should be adopted to maximize the performance of the test. The optimized DHI milk BHB test cut point was lower in herds with a higher prevalence of ketosis compared with low-prevalence herds. When testing in high-prevalence herds, a reduced number of false negatives should be expected despite a slight increase in the number of false positives.

This study demonstrates that the DHI milk BHB test performs reasonably well with a moderate sensitivity, specificity, and level of correlation with serum BHB levels. Some differences were found in the performance of the test depending on DIM and herd-level prevalence. This test could be recommended to monitor ketosis on a herd level when evaluating nutritional management or preventative medicine strategies in herds enrolled in DHI programs with typical or high prevalence of hyperketonemia and in cows that are $<25$ DIM.

\section{ACKNOWLEDGMENTS}

We thank CanWest DHI for financial support and Heartland Veterinary Services for their assistance.

\section{REFERENCES}

Buderer, N. M. F. 1996. Statistical methodology: I. Incorporating the prevalence of disease into the sample size calculation for sensitivity and specificity. Acad. Emerg. Med. 3:895-900. https://doi.org/10 $.1111 /$ j.1553-2712.1996.tb03538.x.

Christensen, J. O., R. R. Grummer, F. E. Rasmussen, and S. J. Bertics. 1997. Effect of method of delivery of propylene glycol on plasma metabolites of feed-restricted cattle. J. Dairy Sci. 80:563-568. https://doi.org/10.3168/jds.S0022-0302(97)75971-X.

Dohoo, I., W. Martin, and H. Stryhn. 2009. Veterinary Epidemiologic Research. 2nd ed. Screening and Diagnostic Tests. VER Inc., Charlottetown, PEI, Canada.

Duffield, T. F., K. Lissemore, B. Mcbride, and K. Leslie. 2009. Impact of hyperketonemia in early lactation dairy cows on health and production. J. Dairy Sci. 92:571-580. https://doi.org/10.3168/jds .2008-1507.

Eicher, R., A. Liesegang, E. Bouchard, and A. Tremblay. 1999. Effect of cow-specific factors and feeding frequency of concentrate on diurnal variations of blood metabolites in dairy cows. Am. J. Vet. Res. 60:1493-1499.

Florkowski, C. M. 2008. Sensitivity, specificity, receiver-operating characteristic (ROC) curves and likelihood ratios: Communicating the performance of diagnostic tests. Clin. Biochem. Rev. 29:S83-S87.

Gordon, J. L., S. J. LeBlanc, and T. F. Duffield. 2013. Ketosis treatment in lactating dairy cattle. Vet. Clin. North Am. Food Anim. Pract. 29:433-445. https://doi.org/10.1016/j.cvfa.2013.03.001.

LeBlanc, S. 2010. Monitoring metabolic health of dairy cattle in the transition period. J. Reprod. Dev. 56. https://doi.org/10.1262/jrd .1056s29.

LeBlanc, S. J., K. Leslie, and T. Duffield. 2005. Metabolic predictors of displaced abomasum in dairy cattle. J. Dairy Sci. 88:159-170. https://doi.org/10.3168/jds.S0022-0302(05)72674-6.

McArt, J. A., D. Nydam, and G. Oetzel. 2012a. A field trial on the effect of propylene glycol on displaced abomasum, removal from herd, and reproduction in fresh cows diagnosed with subclinical ketosis. J. Dairy Sci. 95:2505-2512. https://doi.org/10.3168/jds .2011-4908.

McArt, J. A., D. Nydam, and G. Oetzel. 2012b. Epidemiology of subclinical ketosis in early lactation dairy cattle. J. Dairy Sci. 95:5056-5066. https://doi.org/10.3168/jds.2012-5443. 
McArt, J. A., D. Nydam, G. Oetzel, and C. Guard. 2014. An economic analysis of hyperketonemia testing and propylene glycol treatment strategies in early lactation dairy cattle. Prev. Vet. Med. 117:170 179. https://doi.org/10.1016/j.prevetmed.2014.06.017.

McArt, J. A., D. Nydam, and M. Overton. 2015. Hyperketonemia in early lactation dairy cattle: A deterministic estimate of component and total cost per case. J. Dairy Sci. 98:2043-2054. https://doi .org/10.3168/jds.2014-8740.

Ospina, P. A., D. Nydam, T. Stokol, and T. Overton. 2010. Associations of elevated nonesterified fatty acids and $\beta$-hydroxybutyrate concentrations with early lactation reproductive performance and milk production in transition dairy cattle in the northeastern United States. J. Dairy Sci. 93:1596-1603. https://doi.org/10.3168/jds 2009-2852.

Quiroz-Rocha, G. F., S. LeBlanc, T. Duffield, B. Jefferson, D. Wood, K. Leslie, and R. Jacobs. 2010. Short communication: Effect of sampling time relative to the first daily feeding on interpretation of serum fatty acid and $\beta$-hydroxybutyrate concentrations in dairy cattle. J. Dairy Sci. 93:2030-2033. https://doi.org/10.3168/jds .2009-2141.

Tatone, E. H., T. F. Duffield, S. J. LeBlanc, T. J. Devries, and J. L. Gordon. 2017. Investigating the within-herd prevalence and risk factors for ketosis in dairy cattle in Ontario as diagnosed by the test-day concentration of $\beta$-hydroxybutyrate in milk. J. Dairy Sci. 100:1308-1318. https://doi.org/10.3168/jds.2016-11453.

Tatone, E. H., J. L. Gordon, J. Hubbs, S. J. LeBlanc, T. J. Devries, and T. F. Duffield. 2016. A systematic review and meta-analysis of the diagnostic accuracy of point-of-care tests for the detection of hyperketonemia in dairy cows. Prev. Vet. Med. 130:18-32. https:// doi.org/10.1016/j.prevetmed.2016.06.002.

Youden, W. J. 1950. Index for rating diagnostic tests. Cancer 3:32-35. https://doi.org/10.1002/1097-0142(1950)3:1<32:aidcncr $2820030106>3.0$. co $2-3$. 